\title{
Revista Brasileira de Estudos de População: do nascimento à pós-maioridade
}

\author{
Neide Lopes Patarra* \\ Elisabete Dória Bilac**
}

\begin{abstract}
O objetivo deste artigo é trazer uma reflexão sobre a criação e o amadurecimento da Revista Brasileira de População que, neste número especial, celebra sua maioridade plena - 21 anos. Tributária do início das atividades em população no país, a Rebep nasceu num momento de inflexão da própria evolução dos estudos populacionais. Uma análise de sua trajetória referencia as características, especificidades e dinâmica desse processo, sempre contemplado em sua vinculação com as transformações internacionais que marcaram essas décadas e inserido no contexto do desenvolvimento das ciências sociais no Brasil, de onde deriva sua especificidade. A presente reflexão pode ser considerada um tributo aos muitos companheiros que colaboraram para esse caminho; pode ser também uma contribuição para o encaminhamento do futuro da Abep que se aproxima de seu trigésimo aniversário, tendo ela mesma passado pela inflexão que cercava o momento da criação de sua Revista e por outros momentos marcantes que pavimentaram seu percurso e alavancam suas perspectivas futuras.
\end{abstract}

Palavras-chave: Rebep. Demografia. Estudos de População. Temas de análise demográfica. Fontes de dados. Brasil.

\section{Introdução}

A maioridade da Revista Brasileira de Estudos de População - publicação da Abep e da comunidade de demógrafos - suscita uma reflexão sobre o início, o papel, a trajetória, as implicações e as perspectivas dos estudos demográficos em nosso país. De início, reconhecendo que a Revista nunca se propôs, e nem poderia, a ser o único veículo de divulgação das atividades de ensino e pesquisa em demografia no Brasil, uma análise de sua trajetória referencia as características, especificidades e dinâmica desse processo, sempre contemplado em sua vinculação com as transformações internacionais que marcaram essas décadas e inserido no contexto do desenvolvimento das ciências sociais no país, de onde deriva sua especificidade.

Caudatária do início das atividades em população em nosso meio e da peculiar dinâmica que a demografia teve nos anos 70, no Brasil e na América Latina, a Rebep nasceu num momento de inflexão da própria evolução dos estudos populacionais, que se ressentiam da profunda transformação de todo o processo de produção do conhecimento, de um modo geral, à medida que também foram afetados pela reestruturação produtiva e pela mundialização.

Os objetivos que nortearam a criação da Revista, o desenvolvimento temático gerado pelas reflexões trazidas pela

\footnotetext{
*Pesquisadora titular. Mestrado em Estudos Populacionais e Pesquisas Sociais. Ence/IBGE.

${ }^{* *}$ Pesquisadora do CNPq junto ao Nepo/Unicamp e professora do Programa de Pós-Graduação em Demografia IFCH/Unicamp.
} 
comunidade e colaboradores, sua institucionalização e seu amadurecimento no sentido de uma profissionalização capaz de fazer frente aos "novos tempos" estão registrados nos 22 volumes que compõem o seu acervo.

$\mathrm{Na}$ primeira parte deste ensaio, tentamos reproduzir o momento de seu nascimento -1984 - e as parcerias imprescindíveis para essa concretização; na segunda, procuramos resumir o processo de institucionalização, de formalização e de profissionalização da Revista; na terceira, retomamos os propósitos confrontados com os temas que constituíram, emergiram e se moveram ao longo do seu período de existência e, finalmente, encerramos com uma nota que procura apontar as perspectivas sobre seu papel no contexto do sistema de ciência e tecnologia do Brasil, em um mundo hoje irreversivelmente globalizado.

\section{O nascimento}

A Revista Brasileira de Estudos de População (Rebep) nasceu em 1984, ano da campanha pelas eleições presidenciais diretas no país, marcado por profunda efervescência política e severa crise econômica. Foi lançada no IV Encontro Nacional da Abep, cuja cor oficial foi o amarelo - a cor das "Diretas Já". Os cartazes e a capa dos Anais desse evento eram amarelos e o primeiro número da Revista tinha o fundo verde - verde-amarelo: nacionalista, esperançoso e de abertura política. De várias formas, com muita esperança, marchávamos todos pela liberdade, pela democracia e pelo desenvolvimento do país.

A proposta de sua criação foi aprovada na Assembléia do III Encontro da Abep, momento em que foi eleita a diretoria, presidida por Elza Berquó, e que teve como composição George Martine, Neide Patarra, Diana Sawyer, Ivonete Xavier, Celso Simões e Ricardo Rossato. Essa diretoria - dinâmica, batalhadora e ampliadora - desde o início da gestão empreendeu esforços no sentido de viabilizar o propósito de criar sua revista.

Já avançando na idéia, tornou-se memorável, entre outros momentos, um jantar na casa de Diana Sawyer, em que estavam presentes George Martine e Donald Sawyer e onde foram delineados os detalhes e o conteúdo do primeiro número da Revista.

Nessa ocasião, George e Donald ofereceram dois textos inéditos que se tornaram "clássicos" na bibliografia nacional: Fluxo e refluxo da fronteira agrícola no Brasil; e crescimento e distribuição da população brasileira.

A composição do primeiro volume imprimiu à Revista sua linha editorial: qualidade, oportunidade e inserção de sua produção nos temas e debates mais significativos e inovadores no panorama social e político, concomitantemente à constante presença da especificidade demográfica, com competente utilização de estatísticas e procedimentos metodológicos inovadores e avançados de análise demográfica.

Foi se formando um grupo extremamente entusiasmado, que assumiu como tarefa conjunta a criação da Revista da Abep. Desde o início agregou-se Elisa Helena Maya Fruet como produtora editorial, geógrafa, gaúcha inteligente e competente, que em Paris havia se apaixonado por Ralf Hakkert e com ele veio para São Paulo. Elisa somou forças e, com sua competência e compromisso, imprimiu a qualidade de editoração que caracterizaria a Rebep.

Para sua criação, a colaboração da Fundação Seade foi decisiva. Outro momento memorável foi o dia em que procuramos o diretor executivo daquela instituição, nosso colega e amigo Rubens Murilo Marques, para expor nosso desejo e a necessidade de seu apoio para a montagem da Revista. Rubens, de imediato e também com muito entusiasmo, colocou-nos à disposição todas as facilidades e recursos disponíveis no Seade para a realização de tal empreendimento. Ele mesmo permaneceu conosco, na qualidade de membro do Comitê Editorial, até 1986.

A equipe de planejamento gráfico e visual da Fundação Seade, coordenada por Lea Vitória Lefèvre e composta pelos amigos Antonio Paulo Gomes de Oliveira, Durval de Lara Filho, José Carlos Zeidan Filho e Vera Lucia Fernandes Scannerini, 
iniciou o trabalho de diagramação e montagem do primeiro número. Sentados todos em torno de uma mesa, examinávamos as várias propostas de capa, buscando aquela que melhor representasse nossa intenção, pois não queríamos aquelas imagens tão freqüentes na época da chamada "explosão demográfica", com uma multidão sem forma, um aglomerado plasmado num anonimato objetificante. A capa escolhida buscava expressar nossa concepção de população: a silhueta de pessoas (muitas) movendose - gente em movimento.

Além da capa, foi preparado por essa equipe todo o planejamento gráfico e visual da Revista e, assim, montamos as instruções e normas para a elaboração de originais. Na retaguarda, estavam nossos colegas e amigos demógrafos do então Grupo de Estudos de Análise Demográfica (Geade), sempre prontos a opinar, apoiar e colaborar. Na gráfica da Fundação outra lembrança emocionante - a disposição, a boa vontade, o interesse e o envolvimento de seu pessoal compunham a teia que se montava, num astral de otimismo, confraternização e compromisso que nos unia a todos; durante muito tempo a Revista foi impressa na gráfica do Seade. Logo em seguida, ainda na realização de seus primeiros números, a Revista passou a contar com a valiosa e competente colaboração de Icléia Alves Cury e Alice Miyashiro, que, além de suas participações na Revista, desempenharam uma série de atividades de divulgação da maior importância para a Abep naqueles anos.

O Comitê Editorial foi composto, além da editora responsável e de Rubens Murilo, por nossos colegas Altiva Pilatti Balhana, Helena Lewin, Helio Moura e Jose Alberto Magno de Carvalho - e todos juntos trabaIhamos muito.

Quanto ao seu conteúdo, o primeiro número da Revista contou com a contribuição de outros três textos inéditos - União dos sexos e estratégias reprodutivas no Brasil, de Elza Berquó e Maria Andréa Loyola; Aumento do diferencial por sexo da mortalidade no Estado de São Paulo, de Luis Patrício Ortiz e Lucia Mayumi Yasaki; e Avanços metodológicos recentes na medição dos diferenciais de mortalidade, de Ralph Hakkert -, já anunciando a diversidade e a sensibilidade para temas emergentes que sempre caracterizaram a Revista. Esses textos foram "garimpados" com colegas que puderam colaborar com esse primeiro número; a "garimpagem" ainda durou muito tempo e era difícil manter alguma reserva na "gaveta".

Vale mencionar que, desde o início, foi proposta uma seção de Resenha, que, no primeiro número, contou com a contribuição do inesquecível amigo Candido Procópio Ferreira de Camargo, tecendo comentários sobre o livro Médicos e curandeiros: conflito social e saúde, de Maria Andréa Loyola.

Outra sessão também montada desde o início foi a de Resumos de Pesquisas Concluídas, com a participação, no primeiro número, do Depop/IBGE, naquele momento o nome do grupo de demógrafos do IBGE que, com posteriores siglas, foi fundamental e presente em toda trajetória da Abep e da Revista. O grupo apresentou o "Informe sobre o perfil estatístico de crianças e mães no Brasil: situação de saúde em 1981".

Ousados, saímos com uma tiragem de 1.500 exemplares para serem distribuídos gratuitamente aos associados da Abep e vendidos como exemplar avulso ou assinatura. O preço da assinatura, para 1985 , era de $\operatorname{Cr} \$ 12.000$ ou US\$8,00 e o número avulso custava Cr\$ 7.000 ou US\$5,00!!

\section{O contexto político institucional e o perfil da Revista}

A afirmativa anterior de que a Revista da Abep foi criada num momento de inflexão da trajetória das atividades em demografia e estudos populacionais no Brasil precisa ser mais bem discutida. Como se sabe, essas atividades haviam se iniciado nos anos 60 , inseridas em um conjunto de iniciativas internacionais voltadas, primordialmente, ao crescimento populacional que começara a "explodir" no pós-II Guerra Mundial nos países subdesenvolvidos. Alavancadas principalmente no Cedip/FSP, da USP, e no Cedeplar/UFMG - centros liderados, respectivamente, por Elza Berquó e 
José Alberto Magno de Carvalho - iniciaram-se as atividades de formação de quadros no exterior e as pesquisas, tanto com a utilização de estatísticas oficiais como com a realização de surveys financiados, principalmente sobre atitudes, comportamento e valores voltados à reprodução das famílias e grupos sociais específicos. A partir de 1970, com a criação do Cebrap, agregou-se uma instituição de muita força no debate teórico-crítico e na realização de pesquisas populacionais no Brasil.

Em 1970 foi realizada, no México, a Conferência Latino-Americana de População, que constituiu um marco histórico dessa etapa de desenvolvimento dos estudos demográficos. A Conferência significou um ponto de encontro e de confronto: encontro entre especialistas e pesquisadores de vários países latino-americanos, com predominância da Argentina, México, Chile e Uruguai, desde o início com a fundamental parceria com o Celade; e confronto entre os especialistas desta região e os de fora, principalmente norte-americanos, identificados com uma posição malthusiana diante das questões populacionais dos países latino-americanos. A comunidade latinoamericana de demógrafos ali representada defendia uma posição crítica, em busca de alternativas à postura malthusiana, procurando garantir autonomia na definição de agendas de pesquisas, nas atividades e no delineamento de questões populacionais e das emergentes políticas demográficas. Como as atividades voltadas aos estudos populacionais eram prioritárias no financiamento de instituições internacionais, o confronto evidenciava o desejo de autonomia também em relação a eventuais pressões de financiadores.

A partir dessa Conferência, criaram-se os Grupos de Trabalho da Comissão de População e Desenvolvimento da Clacso e iniciou-se uma década de intensa dinâmica, com encontros sucessivos e uma vasta produção, retratada, entre muitas outras, na chamada série "laranja" de publicações da Clacso. No Brasil, principalmente o Cedip, o Cebrap e o Cedeplar aglutinaram forças e imprimiram um intenso crescimento na área de estudos populacionais, tornandose instâncias primordiais das atividades de pesquisa e do debate em torno das questões estruturais do papel do crescimento populacional em suas mais diversas dimensões e do desenvolvimento econômico e social, com nítida preocupação com as implicações da dinâmica demográfica para as condições de vida e reprodução de grupos sociais específicos.

Na verdade esse momento foi marcado, em nosso meio científico, por uma produção demográfica intensa, envolvida em acalorado debate político-ideológico e caracterizada por uma forte preocupação teórica e globalizante. As reflexões sobre as raízes do pensamento demográfico e o desenvolvimento de uma "demografia crítica", assim como o debate sobre linhas teóricas distintas, acabaram por ampliar sobremaneira o objeto (ou objetos) de estudo da disciplina demografia.

A discussão retomava as raízes do conhecimento demográfico, identificadas, de um lado, com a Aritmética Política, a partir de quando o "contar" as pessoas passa a se constituir em prerrogativa e necessidade do Estado-nação: à medida que o Ancien Régime vai dando lugar à configuração do Estado Moderno, a contagem dos indivíduos e as estimativas da duração de suas vidas tornavam-se imprescindíveis, tanto para fins bélicos como tributários. Posteriormente, com a República, ao Estado coube a prerrogativa de contar seus cidadãos e os registros eclesiásticos perderam completamente sua importância sob este aspecto.

Já na economia política, a transição do feudalismo para o capitalismo suscitava o debate sobre a trajetória das sociedades, em que se podia pensar o papel do crescimento populacional, tendo, de um lado, a concepção malthusiana sobre a inviabilidade do crescimento populacional na evolução das sociedades humanas e, de outro, a crítica marxista, em que o crescimento populacional era fruto das relações capitalistas e só seria resolvido com a transformação estrutural das sociedades.

Essa trajetória imprime à demografia suas conhecidas e perenes "tensões" entre, 
de um lado, as tentativas de articulação das explicações das características e tendências dos componentes da dinâmica demográfica (natalidade/fecundidade, mortalidade e migrações) e, de outro, o desenvolvimento de suas raízes da Aritmética Política, com procedimentos quantitativos específicos para a mensuração de cada um desses componentes, ambas as dimensões absolutamente imprescindíveis para se dar conta da problemática geral do crescimento populacional e do desenvolvimento social.

A demografia, assim, evoluiu marcada pelo esforço de fundir ordens de fenômenos tão diversos, daí as "tensões" que marcaram e marcam até hoje a prática dos especialistas e que se expressam, de modo muito claro, na clássica distinção entre demografia e estudos de população (Hauser \& Duncan, 1975), proposta que se contrapunha a si mesma ao tentar resgatar a demografia como disciplina científica autônoma.

As tentativas de solução para essas tensões básicas assumiram feições distintas, mas capazes de fortalecer a demografia como uma disciplina específica, com métodos e procedimentos próprios, cortes temáticos oportunos e apreciável acúmulo de conhecimento. A configuração das "questões demográficas" mais importantes, em distintos momentos históricos em diferentes situações, de países desenvolvidos e em desenvolvimento, foi um dos caminhos que permitiram esse avanço.

Nos países latino-americanos, a questão demográfica básica nos anos 60 e 70 era o crescimento populacional ocasionado por um declínio acentuado da mortalidade, principalmente nas idades mais jovens, e a manutenção de altos níveis de fecundidade. Tanto na vertente neomalthusiana como naquela "histórico-estrutural", a questão era o crescimento da população, configurando, para uns, uma "explosão demográfica" capaz de obstaculizar os esforços no sentido do desenvolvimento econômico e evidenciando, para outros, que o próprio desenvolvimento econômico poderia se beneficiar desse crescimento populacional, sendo o problema real a questão da mudança econômica estrutural.
A década de 80 significou uma mudança na intensidade e nas características da produção latino-americana e no Brasil. As questões populacionais foram perdendo prioridade nas agendas de financiamento. As sociedades latino-americanas, já distantes do período desenvolvimentista, passaram a exibir com mais vigor os efeitos das crises política e econômica e de períodos de recessão. A própria dinâmica demográfica, sem dúvida, passou a significar uma das dimensões dessa conjuntura social. No transcorrer de suas transições demográficas, as sociedades foram vivenciando declínios em seus níveis de fecundidade e desaceleração de seu crescimento populacional, embora esse processo tenha sido acompanhado de aumento e extensão da pobreza e da miséria.

A não ser em casos isolados, e freqüentemente com pouca base técnica especializada, já não se identificava o crescimento populacional como questão demográfica central dos países latinoamericanos. Passaram a ser enfatizados 0 ritmo e as características do declínio da fecundidade e da estrutura etária em mudança, configurando um novo perfil de demandas sociais. O timing da transição demográfica passou a ser considerado em função do próprio metabolismo demográfico. Emergiram temas como a "onda jovem", enquanto a mudança na estrutura etária e o aumento da longevidade suscitaram a questão da "terceira idade" e, posteriormente, a do idoso, com implicações significativas, entre outras dimensões, para os sistemas de saúde e previdenciário das sociedades envolvidas. Ampliou-se a problemática das migrações quando, na concentração econômica e populacional, o êxodo rural preponderante cedeu lugar às questões da metrópole, das regiões, da periferia urbana e da inserção do migrante na nova configuração do mercado de trabalho.

Deve-se considerar, por outro lado, que a produção científica também foi caracterizada por um acervo muito maior de informações, no que se refere tanto à fecundidade, mediante os surveys realizados, 
como a todos os temas, pelos desenvolvimentos técnicos e de divulgação dos dados dos Censos Demográficos e das PNADs. Os resultados foram sendo divulgados em menor espaço de tempo e por meios magnéticos, sendo que as possibilidades de desagregação da informação mediante o acesso a microdados resultaram em análises quantitativas muito mais refinadas.

A Rebep surgiu, portanto, nesse momento de inflexão. $\mathrm{Na}$ apresentação de seu número-lançamento, assinada pelo Comitê Editorial, recorreu-se às motivações, aspirações e dinamismo da comunidade abepiana:

\begin{abstract}
A aspiração da comunidade científica, manifesta há algum tempo no seio da $A B E P$, deriva da ausência de uma publicação periódica, especializada, de âmbito nacional, versando sobre assuntos populacionais. Essa modalidade de comunicação entre especialistas e destes para áreas afins, justifica-se plenamente considerando-se a relevância da produção científica brasileira na área de População, como atestam, entre outras fontes bibliográficas, os Anais do I, II e III Encontros Nacionais da ABEP (Comitê Editorial,1984: 2).
\end{abstract}

Estava presente o contexto que se vivia:

(...) a conjuntura extremamente importante que o Brasil atravessa, em função de acentuadas mudanças na sua dinâmica demográfica, as quais devem ser estudadas e divulgadas, bem como suas inter-relações com processos sociais também em ritmo acelerado de mudança, agravada pela crise atual. Esta nitidamente interfere nas condições de vida e de reprodução de grupos sociais específicos (Comitê Editorial,1984: 2)

Além disso, estavam também explicitadas a importância atribuída à historicidade dos fenômenos como dimensão intrínseca do saber demográfico, comprometido com a perspectiva histórica das questões populacionais, e a especificidade das fontes de dados e procedimentos de análise da demografia histórica.

Ressalta-se, ainda, desde seu início, a preocupação didática, em função do crescimento das atividades de ensino no país. Finalmente, a Revista colocava como objetivo um diálogo contínuo com órgãos públicos, considerando, já naquele momento, tratar-se de uma dimensão fundamental a qualquer tentativa de implantar, ampliar ou modificar a ação de políticas públicas.

$O$ contexto em que se circunscrevia a Revista decorria, portanto, do profundo debate presente na comunidade demográfica internacional, mas que, na América Latina, de um modo geral, assumira contornos muito próprios. O debate, como vimos, trazia para a discussão a própria natureza da demografia, seu objeto e método, pondo em questão, portanto, o próprio conceito de população.

Este debate, embora já estivesse se arrefecendo nos anos 80, sem dúvida, imprimiu sua marca na definição dos objetivos e no nome da Revista, como, aliás, tinha marcado a própria constituição da Abep, em 1976.

Nesta declaração de objetivos, nota-se, em primeiro lugar, um entendimento bastante abrangente de quais sejam os temas pertinentes aos especialistas em população e, portanto, merecedores de acolhida na Revista, perspectiva esta derivada de um conceito igualmente amplo de população, envolvendo suas dimensões tanto quantitativas quanto qualitativas. Desta perspectiva, no estudo dos temas populacionais, enfatiza-se a inter-relação entre a análise demográfica stricto sensu e as análises dos processos sociais.

Não se tratava, com isso, de reafirmar a antiga distinção entre demografia e estudos de população, mas, ao contrário, de buscar superá-la em uma percepção ampla da demografia como ciência social. $\mathrm{E}$, mais ainda, entendida como um campo disciplinar, em que a produção do conhecimento ocorre visando também o embasamento de políticas públicas.

Esta opção é diametralmente oposta, por exemplo, à assumida pelos mentores da Demography, a revista da PAA (Population Association of America). Em seu artigo-testemunho, por ocasião do 30 으 ano da Demography em 1993, Donald Bogue aponta, entre os objetivos iniciais do periódico, que o mesmo pretendia ajudar a PAA a fortalecer sua imagem como organização científica e superar sua orientação para "problemas de população". A revista 
foi nomeada Demography (e não Population Problems - ou outro título similar) para the dar o necessário ar de correção:

The journal should help PAA strenghten its 'image' as a scientific organization and outgrow its "population problems orientation". The journal was named Demography (rather than 'Population Problems' or some similar title) in order to give it the desired air of correctness (Bogue, 1993: 520).

Por outro lado, o sistema de educação superior já vinha experimentando mudanças que se acentuaram nos anos seguintes, com a democratização do país, no sentido de sua maior institucionalização: a Capes e o CNPq passaram por reformulações e adotam políticas mais agressivas de apoio à pesquisa e à pós-graduação, que envolviam também o estabelecimento de critérios mais claros (porém também muitas vezes polêmicos) para avaliação do desempenho e da produtividade de pesquisadores, professores e pós-graduandos. Estas mudanças se traduziram em maiores pressões para a publicação de artigos resultantes de pesquisas.

\section{Rumo à profissionalização}

Ao longo de seus 21 anos de existência, a Rebep contou com seis editores responsáveis: Neide Patarra, de 1984 a 1989; Maria Coleta de Oliveira, de 1990 e 1993; Teresa Sales, de 1994 a 1996; Ana Amália Camarano, de 1997 a 1999; Elisabete Bilac, de 2000 a 2004; e Carlos Eugenio de C. Ferreira, a partir de 2005.

Teve quatro capas: a segunda suscita um olhar ao cotidiano da população; a seguinte insere a população em seu território nacional, quem sabe sugerindo a inclusão e o pertencimento de toda a população à sociedade nacional; a última caracteriza a etapa da maioridade - abstrata, sóbria.

Os comentários dos editores, ao assumirem a responsabilidade pela Revista, evidenciam o reforço do propósito inicial, ao mesmo tempo em que refletem o objetivo de captar a evolução da produção científica voltada às questões populacionais em nosso meio. Assim, ao assumir sua tarefa,
Maria Coleta F. A de Oliveira, anunciando uma nova etapa da Revista, inaugurou a seção Ponto de Vista e ampliou seu espaço de debate, além de imprimir um caráter de ensaio às Resenhas e às Notas de Pesquisa (Oliveira, 1990).

A editora seguinte, Teresa Sales, iniciou sua tarefa com o número comemorativo dos dez anos da Revista (Sales, 1994), reforçando a importância dos estudos populacionais e apontando a emergência da questão racial, abordada por duas importantes contribuições na temática que ganhava força como questão populacional no Brasil.

Em 2000, a Revista apresentou-se com novo visual, acompanhado de mudanças visando um maior nível de profissionalismo na publicação e buscando aliar a qualidade formal à qualidade de conteúdo. A editora enfatiza a importância de uma temática variada que deveria expressar a diversidade de interesses de pesquisa existentes na comunidade brasileira de demógrafos (Rebep, 2000).

$\mathrm{Na}$ verdade, ao longo de seus 21 anos de existência, a Revista foi aprimorando seu aspecto formal rumo à sua profissionalização. Já em 1988, mais uma contribuição valiosa da equipe da Fundação Seade configurou-se na indexação dos artigos, elaborada pela equipe do Sistema de Documentação sobre População no Brasil - Docpop, daquela instituição - publicada como parte integrante de seu v.5 n.1, contendo um resumo de cada um dos artigos indexados (Rebep, 1988).

A essa primeira indexação deu-se continuidade em 1995, quando foi elaborado o Índice Remissivo 1989-1995 (Rebep, 1995). Ambos obedecem a uma mesma sistemática e são apresentados os resumos em português e em inglês dos artigos do período classificados por grandes temas. É interessante observar que, em boa medida, os temas indexados refletem a dinâmica da produção científica e a própria evolução dos estudos populacionais em nosso meio. Em 2004, foi retomado o processo de indexação. O novo índice está em formato eletrônico e reúne todos os volumes da Rebep, desde o número 1 , permitindo a busca por 
palavras-chave, por autor e título do artigo, sumários e abstracts. Este índice deverá ser instalado na página da Abep e, a partir dos resultados da busca, permitirá o acesso aos textos integrais de todos os artigos veiculados pela Revista, que já estão disponibilizados na página em formato eletrônico. Sua produção teve o apoio financeiro do CNPq.

Foram publicados 22 volumes da Revista, com periodicidade semestral, compreendendo, portanto, um conjunto de 44 números. Essa produção contemplou, desde o início, artigos inéditos voltados à produção da comunidade de demógrafos e áreas afins, além de números especiais que privilegiaram temáticas emergentes.

\section{Propósitos e temas}

Examinando sua produção desde a criação, pode-se constatar que a Revista vem conseguindo manter seu projeto original, ao mesmo tempo em que constantemente o atualiza, para dar conta dos impactos e das implicações provocados, na nossa população, pelas profundas transformações sociodemográficas e econômicas vividas no Brasil.

Com o intuito de oferecer uma visão de conjunto dessa produção, foram elaboradas as três tabelas aqui apresentadas, procurando traçar o perfil da Revista a partir de algumas características apreendidas dos artigos publicados ao longo de seus 21 anos de existência.

A classificação temática obedeceu à indexação dos artigos da Rebep e os dados foram agregados por qüinqüênios, entre 1984 e 1998 e um último período de seis anos, de 1999 a 2004.

\section{O período 1984-1988}

Como se pode verificar na Tabela 1, o primeiro qüinqüênio reflete bem a conjuntura e a concepção temática abrangente da Revista. O principal tema do período correspondeu a políticas, planos e programas, abordado em cerca de $20 \%$ dos artigos. É bem verdade que este excepcional desempenho deveu-se, em grande parte, à publicação na Revista, em edição especial comemorativa dos dez anos da Abep, dos trabalhos apresentados nas notáveis sessões do V Encontro Nacional, de 1986, onde especialistas de diversas partes do globo discutiram as políticas de população em diferentes países e regiões. Entretanto, tal fato apenas reforça o argumento sobre a importância, naquele momento, desta discussão, escolhida pela Abep para marcar seu aniversário de dez anos.

Com menor ocorrência, dois outros temas são também característicos da discussão do período: dinâmica demográfica; e desenvolvimento socioeconômico. $\mathrm{Na}$ verdade, a separação temática é mais uma questão de ênfase, pois a discussão de políticas de população tende a passar pela análise da dinâmica demográfica, ou seja, dos efeitos da articulação entre mortalidade, fecundidade e migrações na conformação do crescimento populacional, dado um determinado quadro de desenvolvimento socioeconômico que se objetiva transformar.

De certo modo, cada um destes três temas envolve a discussão dos outros dois e, em conjunto, respondem por cerca de um terço dos artigos publicados na Revista.

Os temas demográficos clássicos mortalidade, fecundidade e migrações também se fazem presentes e são responsáveis por outro terço dos artigos. Nota-se que, já neste qüinqüênio, o tema distribuição espacial da população destacase como dimensão específica no campo dos estudos migratórios, enquanto efeito inequívoco da complexidade atingida pelo processo de urbanização brasileiro.

Também foi acolhida na Revista a discussão sobre força de trabalho, de extrema importância em face da longa crise econômica dos anos 80 , com pequeno interlúdio de recuperação entre 1984 e 1986, sendo sucedido pela desaceleração da atividade econômica e pela hiperinflação no final da década, anunciando já a reestruturação produtiva nos anos 90 .

O tema nupcialidade e família também teve, neste período, seu melhor desempenho na história da Rebep, ocupando o segundo lugar. Esta posição de vantagem coincide com os primeiros indícios das 


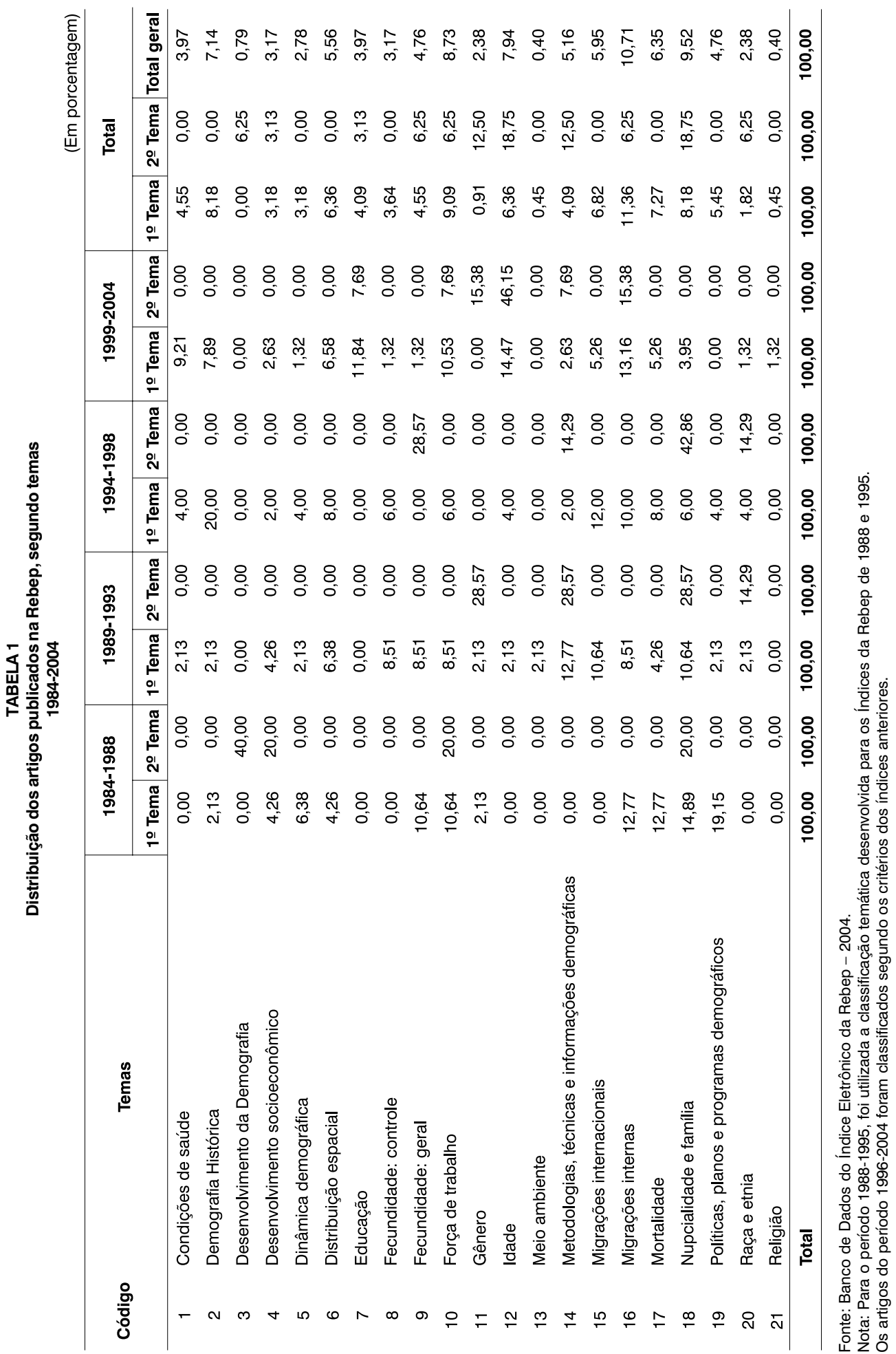


profundas transformações que se iniciavam nas famílias brasileiras, captados pelo Censo de 1980 e pelas PNADs da década, que passavam pelo crescimento dos domicílios unipessoais e daqueles chefiados por mulheres e pela redução do tamanho do grupo familiar, principalmente devido à queda da fecundidade, mas afetado também pelo aumento dos divórcios e separações, particularmente após a Constituição de 1988.

Nota-se ainda que a contribuição da demografia histórica, enfatizada no documento de criação da Revista, foi muito pequena neste período, uma vez que os demógrafos-historiadores encaminham sua produção também para os periódicos especializados em história.

\section{O período 1989-1993}

No segundo qüinqüênio - 1989 a 1993 é interessante observar a predominância de textos inseridos na rubrica metodologias, técnicas e informações demográficas, com $12,8 \%$ da produção da Revista, reforçando a sempre presente contribuição dessa dimensão na trajetória da Rebep.

Por sua vez, os textos sobre nupcialidade e família continuaram a ter representação expressiva na Revista (10,6\% dos 47 textos do período) e, associados àqueles classificados nos temas fecundidade-controle e fecundidade-geral, compreenderam $17,0 \%$ dos artigos.

Foi neste momento que surgiu, para permanecer, o tema das migrações internacionais, inicialmente publicado no v. 8 n.1/2 e reforçado no número seguinte (v.9, n.1), com artigos pioneiros sobre a saída de brasileiros e sobre brasileiros vivendo no exterior. A partir de então, o tema sempre esteve presente, seja em reconstruções históricas sobre a imigração para o Brasil, seja no tema das metodologias apontando as implicações do novo fenômeno de saída de brasileiros para as projeções demográficas do país e a necessidade de fontes de dados para sua mensuração e análise. Neste período, os artigos sobre migrações internacionais representaram $10,6 \%$ da produção da Revista, mas o tema compareceu também na seção Ponto de Vista.

Embora com presença reduzida em relação ao qüinqüênio anterior, a temática das migrações internas permaneceu relevante, abrangendo $8,5 \%$ dos artigos.

Esse momento também coincide com a emergência da problemática população/ meio ambiente e, da mesma forma, evidencia-se o aparecimento da dimensão raça e etnia, que se faz presente tanto como tema principal, com a emergente linha de estudos sobre demografia de povos indígenas, quanto associada a outros temas e, neste segundo caso, envolvendo estudos dos diferenciais por cor entre brancos e negros.

\section{O período 1994-1998}

O terceiro qüinqüênio - 1994 a 1998 envolveu 50 artigos, com predominância da demografia histórica, que compareceu tanto em artigos nos números regulares da Revista, no período, como no dossiê apresentado no v. 14 n.1/2 de 1997, compondo, assim, $20 \%$ da produção. Outro dossiê foi publicado no mesmo período - o de migrações internas - no v.15 n.2, de 1998. Em conjunto, os artigos sobre migrações internas e distribuição espacial da população, temas evidentemente relacionados entre si, responderam por $18 \%$ da produção do período. Migração internacional continuou em destaque, com seis artigos, ou 12\% da produção.

Nos estudos sob a rubrica fecundidadecontrole, continuaram significativos os assuntos relacionados à esterilização e ao aborto. Já o tema fecundidade-geral apareceu em segundo lugar, no período, associado em boa parte com os estudos sobre diferenciais por raça.

Neste qüinqüênio registra-se, ainda, a ocorrência da Conferência do Cairo sobre População e Desenvolvimento, realizada em 1994, sendo publicada na Revista uma síntese comentada de seu significado. Nos volumes subseqüentes, os impactos da Conferência tornaram-se evidentes nos debates sobre a nova conceituação de saúde e direitos reprodutivos e seus 
desdobramentos em termos de pesquisa, ensino e políticas públicas.

Finalmente, também se observa, nesse período, a emergência da questão do envelhecimento populacional, subsumida na rubrica idade.

Além disso, nesse qüinqüênio foi publicado o primeiro volume da versão em inglês da Revista - Brazilian Journal of Population Studies v. 1, 1997/1998 -, planejada para ter periodicidade bienal. A justificativa para tal iniciativa, apontada na Nota Editorial desse primeiro volume, era a necessidade, constantemente sentida na comunidade de demógrafos, de divulgar sua publicação em âmbito internacional, o que era limitado pela pouca divulgação do português nas comunidades afins de outros países, onde o idioma inglês é moeda corrente:

The Brazilian demographic community, though well-established and productive, suffers from a linguistic barrier which inhibits the dissemination of its work. The decision to publish an English-language version of our journal ..., seeks to attenuate this problem,. This inaugural issue was conceived as a selection of papers of historical importance to the dvt of Brazilian population studies during the period following the creation of ABEP(Editor's note., Brazilian Journal of Population Studies, v.1 1997/1998:3).

Já o segundo volume da versão em inglês (Brazilian Journal of Population Studies, v.2 1999/2000) teve como objetivo a apresentação de artigos que tratavam de questões significativas para o entendimento das tendências recentes da dinâmica demográfica brasileira e suas implicações para o futuro. Infelizmente, por causa de seu alto custo financeiro, o projeto "Rebep em Inglês" não pôde ter prosseguimento.

\section{O período 1999-2004}

Nestes seis anos consolidaram-se, na Rebep, algumas das tendências observadas nos períodos anteriores. A mais evidente é a diversidade temática, configurando a permanência, entre nós, dos estudos de população como um campo multifacetado, envolvendo interesses diversos e cambiantes. Além disso, fica muito clara a mudança de inflexão temática. Considerando-se a distribuição porcentual dos artigos por tema principal (Tabela 1), neste período eles estão classificados em 17 assuntos distintos, permitindo uma ordenação em 11 postos. Neste ranking, entre os campos clássicos de análise demográfica, apenas o tema migrações internas garante uma posição de destaque, responsabilizando-se por $13,16 \%$ dos artigos e ocupando a terceira colocação. Os demais, como fecundidade, mortalidade, migrações internacionais e dinâmica demográfica, mantêm presença muito mais discreta, em face de temas emergentes, como idade (neste período representada por um grupo etário específico: os jovens), que lidera o ranking com perto de $15 \%$ dos artigos, ou ainda educação, tema principal de $12 \%$ do total de textos.

Entretanto, deve-se considerar que, se por um lado o tema das migrações internas corresponde a uma oferta espontânea, decorrente da existência de interesse já consolidado na comunidade demográfica, por outro, o grande volume de artigos sobre os temas juventude e educação representou uma resposta da comunidade a uma demanda intencional construída pela Rebep e pela Abep, através de solicitações de artigos para elaboração de números temáticos, em 2000 e 2001.

O sucesso desta política, que se evidencia também pelo fato de que, no período analisado, se concentraram praticamente $35 \%$ de toda a produção veiculada pela Rebep, suscita reflexões sobre o desenvolvimento futuro da Revista e seu papel na indução do desenvolvimento de determinados temas no âmbito dos estudos de população. Não há dúvida de que os números temáticos têm um forte apelo. A oferta de artigos espontâneos, em situações habituais, nunca chegou a se igualar àquela referente a estes números especiais. Isto sugere que a Rebep pode desempenhar papel importante na conformação do desenvolvimento da demografia no Brasil, mediante o recurso a números temáticos de modo sistemático - embora, obviamente, não de modo exclusivo para estimular a produção em temas 
considerados importantes, mas que em determinadas conjunturas apresentam pequena cobertura.

O caso da temática "juventude" é exemplar: apesar da reconhecida importância de fenômenos demográficos como a "onda jovem", da participação dos jovens na mortalidade por causas externas, da complicada relação entre os jovens e o mercado de trabalho, ou ainda da controversa questão da gravidez na adolescência, o tema não esteve presente na Revista de modo significativo antes que fosse gerada uma demanda específica por ele.

Associada a esta diversidade temática há outra dimensão significativa: o caráter interdisciplinar emprestado ao tratamento dos temas. Não se trata apenas do fato de que a Revista configura-se como interdisciplinar para além de sua diversidade temática, uma vez que cada tema é abordado sob diferentes óticas, mas também do fato de que os artigos crescentemente buscam construir suas respectivas problemáticas e os concomitantes quadros explicativos na intersecção de várias disciplinas. Se a demografia, como pretendia Stycos, é em si mesma uma "interdisciplina" (apud Caldwell, 1996: 306), esta característica parece acentuar-se nos anos recentes e talvez esteja contribuindo para a natureza cada vez mais coletiva dos artigos. Dos trabalhos publicados na Revista neste período, $50 \%$ estão assinados por dois ou mais autores.

\section{Fonte de dados e informações}

As Tabelas 2 e 3 foram montadas a fim de se ter uma visão de conjunto das fontes de dados e informações que subsidiam a produção da Revista e como evoluíram ao longo de sua trajetória.

A Tabela 2 permite uma apreensão geral da relação entre fontes e temas ao longo da história da Revista. Verifica-se que temas como distribuição espacial da população, fecundidade geral e migrações internas permanecem profundamente tributários dos dados do Censo Demográfico, que, nestas áreas, fornece insumos para mais de $40 \%$ dos artigos.
Em termos gerais, cerca de $20 \%$ dos artigos, distribuídos em 18 das 20 áreas temáticas arroladas, utilizam os dados do Censo. Em segundo lugar como principal fonte e por número de áreas temáticas está a PNAD, com $11 \%$ dos artigos em 14 áreas. As demais fontes apresentam utilização bem mais reduzida, reflexo de sua própria multiplicidade. Algumas áreas temáticas destacam-se pela diversidade das fontes de dados utilizadas: mortalidade e força de trabalho, por exemplo, recorrem respectivamente a 15 e 14 das categorias de fontes de dados arroladas na Tabela 3.

Por outro lado, apesar de múltiplas, a grande maioria das fontes de dados é de natureza quantitativa. Já a pesquisa qualitativa, mencionada em apenas $8 \%$ dos artigos, tem importância relativa maior em algumas áreas do que em outras, destacando-se sua utilização nos estudos sobre controle da fecundidade, idade, gênero, migrações internacionais, condições de saúde e nupcialidade e família.

A natureza das fontes evidencia o caráter empírico da esmagadora maioria dos trabalhos publicados. Ao se considerar que a categoria "não se aplica" refere-se, por exclusão, a trabalhos que não utilizam dados empíricos e são de natureza mais conceitual, como ensaios ou reflexões teóricas, pode-se constatar a reduzida freqüência com que este tipo de artigo aparece ao longo da história da Revista, a não ser no período 1994-1998 (Tabela 3). Porém, sua presença inusitadamente intensa neste qüinqüênio deve-se a algumas iniciativas pontuais, propostas por Grupos de Trabalhos da Abep e acatadas pelo Conselho Editorial, de publicação de dossiês temáticos, destinados a cobrir o Estado das Artes em determinados campos e de mesasredondas ocorridas nos Encontros da Abep, que ensejaram reflexões consideradas de algum modo inovadoras.

As fontes de dados utilizadas também apontam algumas novas tendências do período recente. Se o Censo Demográfico continua sendo a fonte inegavelmente mais consultada pelos estudiosos de população, nota-se que as PNADs foram também bastante utilizadas. 


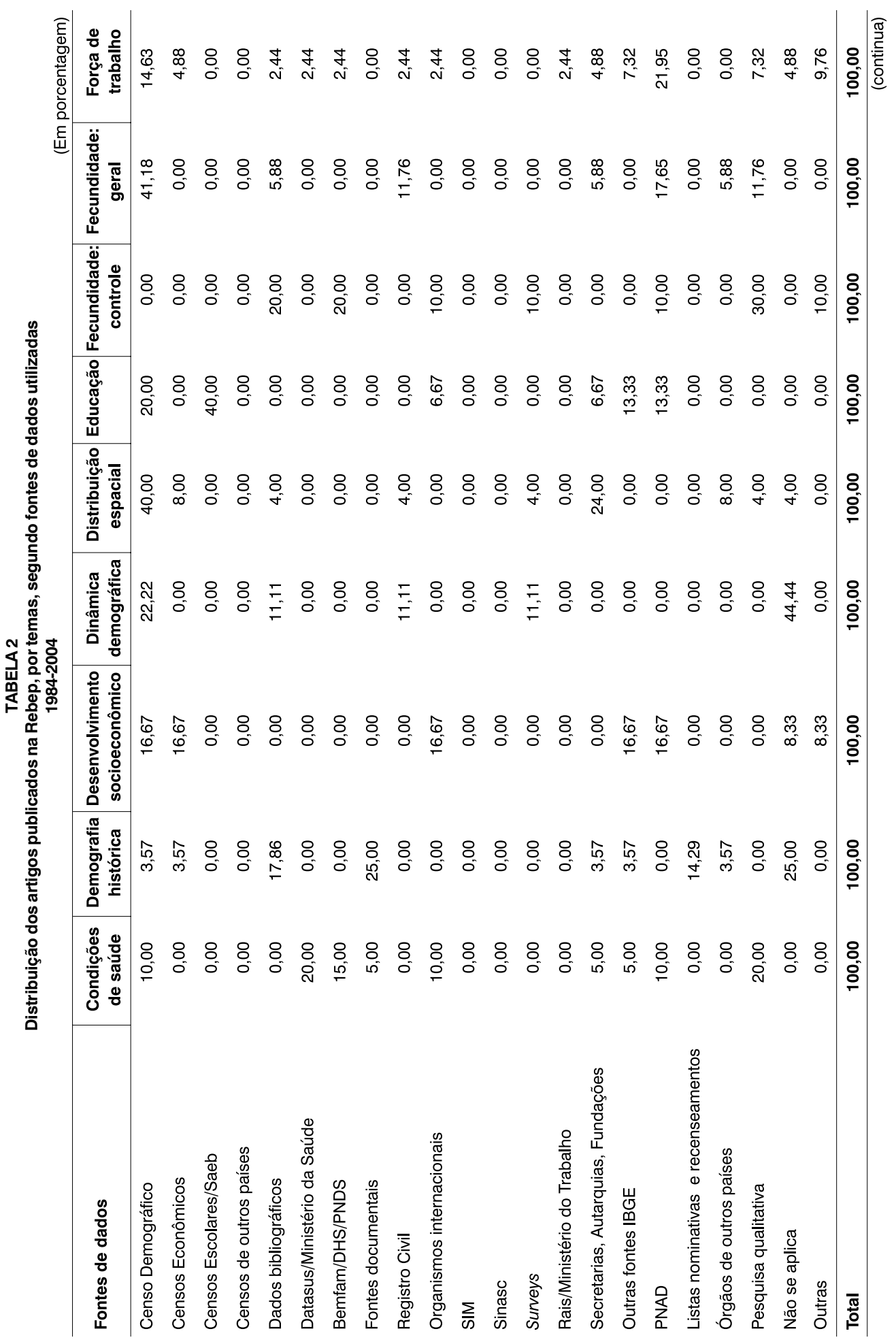




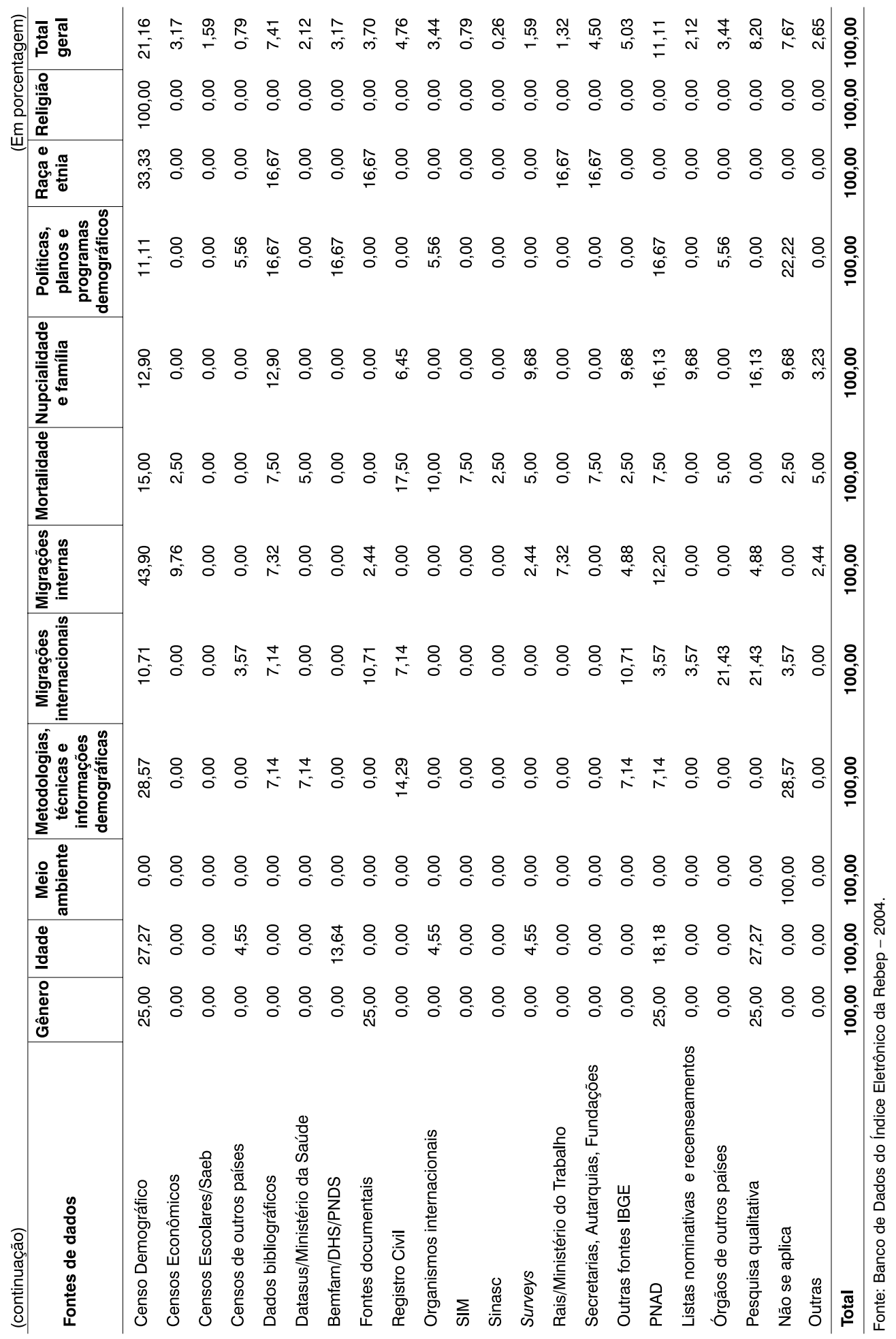




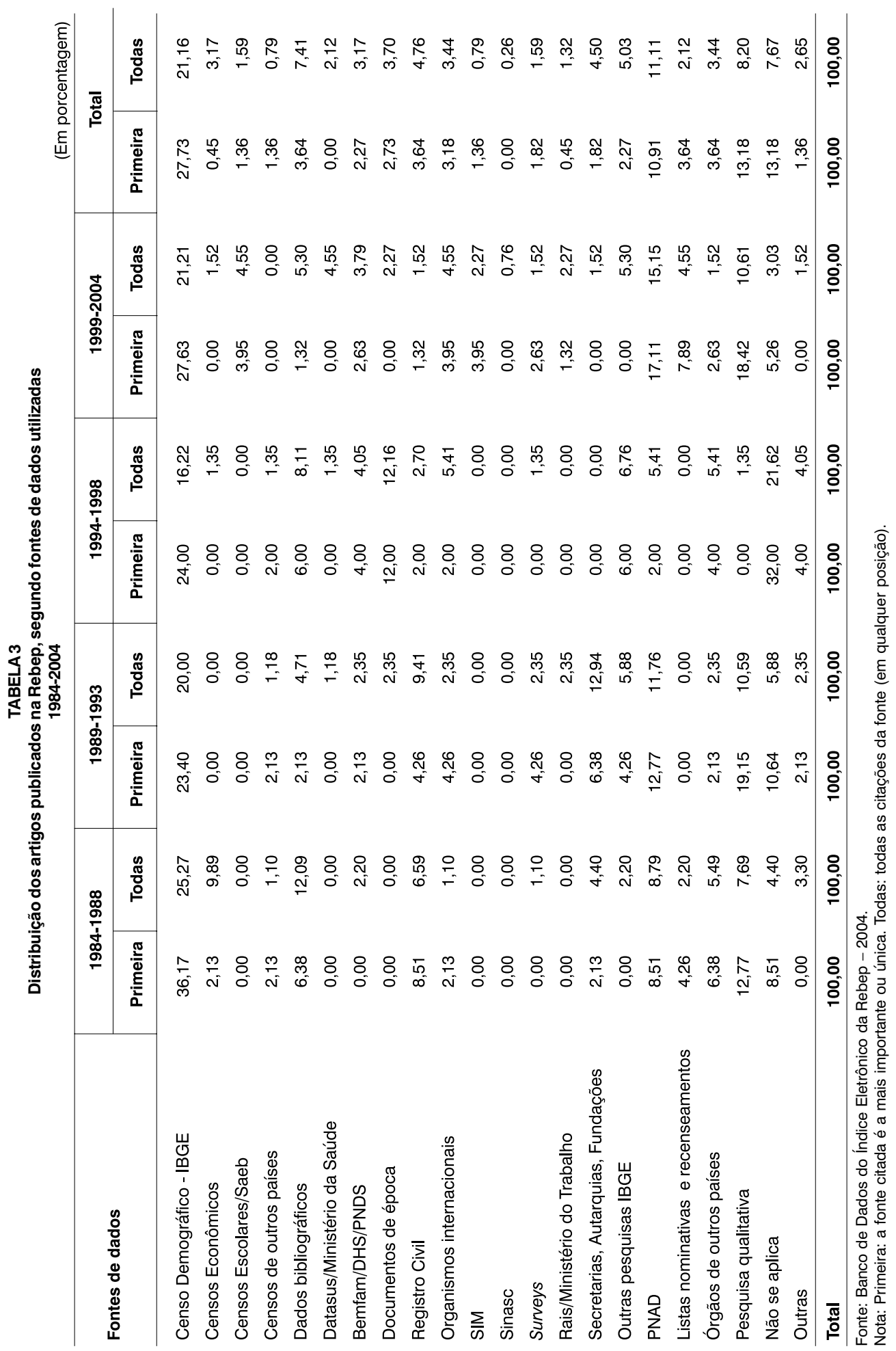


A construção de sistemas de informação, acessíveis on-line a partir dos dados centralizados nos Ministérios e órgãos governamentais, também tem permitido a diversificação das fontes de dados. Notase, nesse período recente, a entrada em cena, embora ainda com utilização modesta, do Datasus, SIM e Sinasc.

No geral, cerca de $70 \%$ dos trabalhos publicados pela Revista, neste período, utilizaram dados quantitativos como primeira fonte de informação, as listas nominativas e recenseamentos utilizados nos artigos de demografia histórica. Já os textos que usaram dados gerados por pesquisa de natureza qualitativa, envolvendo trabalho de campo de natureza antropológica ou sociológica, são mais raros, embora apresentem crescimento significativo em relação ao período anterior.

De um modo geral, portanto, a produção acadêmica veiculada na Rebep caracterizase pela grande diversidade temática e pelo emprego de múltiplas fontes de dados, predominantemente de natureza quantitativa, destacando-se sobremaneira o Censo Demográfico. Este perfil consolidouse no período 1999-2004

\section{A maioridade e suas perspectivas}

Não é demais repetir que, com uma periodicidade semestral e uma média de pouco mais de dez artigos anuais até o presente momento, a Rebep não contempla toda a produção demográfica brasileira. Esta se encontra espalhada em várias revistas - Revista Brasileira de Estatística, Cadernos de Saúde Pública, Revista Brasileira de Ciências Sociais, Estudos Feministas, para mencionar apenas algumas.

Por outro lado, deve-se considerar que, a partir dos anos 90 , todo o processo de produção de conhecimento acadêmico apresenta-se fortemente marcado pela informatização. $\mathrm{O}$ acesso a grandes bancos de dados, as opções de processamento em tempo recorde destes dados e as novas possibilidades de modelagem matemática trazidas pela computação produziram metodologias e técnicas de análise mais sofisticadas e intensificaram extremamente o ritmo da pesquisa. Produz-se mais, em menos tempo. Surgem novos periódicos científicos, alguns com grande interface com os interesses temáticos da Revista. Ao mesmo tempo, expande-se o sistema universitário, com a criação de novas universidades e centros universitários, em sua maioria privados. Aumentaram não apenas as graduações nas diversas áreas, mas também as pós-graduações, principalmente nas universidades públicas. Não seria exagero afirmar que o sistema nacional de Ciência e Tecnologia mudou e continua mudando profundamente.

Em conseqüência, alteraram-se também os processos de avaliação da qualidade da produção acadêmica e dos veículos disseminadores desta produção. Assim é que, no âmbito da Capes (Coordenação de Aperfeiçoamento do Pessoal de Nível Superior - do MEC) e visando atender precipuamente a necessidade de avaliação da pós-graduação, foi constituído o sistema Qualis, de classificação dos veículos utilizados pelos programas de pósgraduação para a divulgação da produção intelectual de seus docentes e alunos. Por este sistema, as publicações científicas utilizadas para dar vazão à produção docente e discente são enquadradas em categorias indicativas da qualidade - A, B ou C - e do âmbito de circulação dos mesmos - local, nacional ou internacional. A classificação de um periódico pode variar nas diferentes áreas de conhecimento, ou seja, pode ser classificado como Qualis A em determinada área, para cujo desenvolvimento é considerada importante, e Qualis $B$ ou $C$ em outra área em que sua participação é menor. A conseqüência natural deste processo é que os autores procuram encaminhar sua produção para aqueles periódicos de melhor classificação na área em que atuam. No sistema Qualis, o caráter interdisciplinar da Rebep a obriga buscar estar bem classificada em diversas áreas simultaneamente, o que não é uma tarefa fácil.

Outra importante referência de qualidade foi criada com a instituição da SciELO - Scientific Electronic Library Online, resultante da parceria entre a Fapesp (Fundação 
de Amparo à Pesquisa do Estado de São Paulo) e a Bireme (Centro Latino-Americano e do Caribe de Informação em Ciências da Saúde) e que posteriormente passou a contar também com o apoio do CNPq. Como o próprio nome indica, a SciELO é uma biblioteca eletrônica que abrange uma coleção selecionada de periódicos científicos brasileiros. Seu objetivo é implementar o desenvolvimento de uma metodologia comum para preparação, armazenamento, disseminação e avaliação da produção científica em formato eletrônico. Para compor a seleta coleção de periódicos indexados pela SciELO e através dela disponibilizada em formato eletrônico, uma publicação científica tem que atender a rigorosos critérios de qualidade tanto substantiva quanto formal, que foram incorporados também pelos órgãos de fomento científico, como o CNPq.

Evidentemente, este contexto geral passa a exigir dos periódicos científicos uma maior profissionalização de todos os seus procedimentos de produção e distribuição. Assumindo este desafio, a Rebep pôs em andamento um profundo e longo processo de mudança interna, ainda em curso, que objetiva, além de sua inserção tanto no sistema Qualis quanto na SciELO, a consolidação de sua posição como periódico de referência dos Estudos de População no país.

As mudanças que vêm sendo empreendidas envolvem todas as etapas do processo produtivo, descritas a seguir pela sua ordem lógica e não pela ordem cronológica de sua implementação.

1. Filiação da Rebep à Associação Brasileira de Editores Científicos, com o intuito de manter o corpo editorial da Revista sempre atualizado no campo da editoração científica, no que diz respeito aos seus aspectos tanto formais quanto substantivos.

2. Constituição de um banco de pareceristas por especialidade, instituição e titulação, recrutados não apenas entre os abepianos mas também nas áreas afins, de modo a diversificar o corpo de pareceristas e evitar sua concentração em poucas instituições.
3. Compatibilização das normas de apresentação dos originais para publicação com as versões mais recentes das normas técnicas editoriais produzidas pela ABNT. Estas normas são constantemente revisadas, acompanhando eventuais mudanças introduzidas pela ABNT.

4. Padronização do conteúdo mínimo dos pareceres solicitados aos pareceristas ad hoc, mediante elaboração de formulário próprio para emissão de pareceres, com instruções bastante específicas sobre os critérios de avaliação da qualidade dos artigos.

5. Modificações no Regimento Interno da Revista e criação de uma rotina de solicitação de trabalhos, através da própria Revista, do Informativo da Abep e da página da Associação, objetivando maior agilidade na captação de artigos e na regularização de seu fluxo.

6. Envolvimento dos GTs da Abep no processo de captação de artigos e de produção de números temáticos.

7. Estrito controle de qualidade da linguagem dos textos publicados, mediante rigorosa revisão tanto dos textos em português quanto dos abstracts.

8. Alteração do projeto gráfico da Revista e observância rigorosa das normas da ABNT para publicações científicas na composição gráfica de cada volume.

9. Planejamento de todo o processo de produção da Revista, de acordo com cronograma preestabelecido, buscando minimizar atrasos na publicação.

Estas mudanças, que representam um grande esforço dos sucessivos Conselhos Editoriais do período, permitiram que a Rebep conseguisse atingir dois de seus objetivos: nos últimos anos, tem sido renovada anualmente sua classificação Qualis A, para as áreas de Planejamento Urbano e Regional/Demografia e Antropologia; no início de 2005, a Revista foi 
avaliada pelo Comitê Consultivo da SciELO e teve recomendada sua inclusão na coleção SciELO-Brasil. Ao completar 21 anos de idade, a Rebep parece assim ter alcançado uma posição de periódico científico nacional respeitável.

Quais seriam as perspectivas para o futuro? Como mencionado anteriormente, as mudanças na Rebep deverão continuar. E nestes tempos globais, em que a produção do conhecimento cada vez mais subordina-se à lógica da produção just on time, com intervalo mínimo de tempo entre produção e circulação, cabe perguntar se a Rebep não deveria procurar tornar-se uma revista internacional.

Por revista internacional, entende-se aqui uma publicação que apresente duas características importantes: em primeiro lugar, um Conselho Editorial ampliado, envolvendo representantes de instituições acadêmicas de diferentes países; em segundo lugar, um projeto editorial que contemple a possibilidade de publicação multilíngüe, que pudesse incorporar textos escritos também em inglês, francês e espanhol, além daqueles produzidos em nossa inculta e bela língua portuguesa.

A sugestão não é descabida. $O$ inglês e o francês são as línguas oficiais da lussp/ Uiesp - da União Internacional para o Estudo Científico da População, principal associação mundial dos estudiosos de população. A recente criação da Alap Asociación Latinoamericana de Población, que busca a integração regional, sem dúvida estimulará o intercâmbio e a cooperação científica entre os países latino-americanos e entre os estudiosos de línguas espanhola e portuguesa. Por que a Rebep não poderia ser um dos porta-vozes desta integração? Apesar de recentemente ter sido formado

\section{Referências bibliográficas}

ABEP. Nota do editor. Revista Brasileira de Estudos de População, Campinas: Abep, v.17, n.1/2, jan./dez., p. 3, 2000.

ABEP. Índice Remissivo 1989-1995. Revista Brasileira de Estudos de População, Campinas: Abep, v.12, n.1/2, jan./dez., p. 1-84, 1995. um Comitê internacional de publicações junto à Alap, tal fato não invalida a proposta do ponto de vista da Rebep. Seguramente, haverá aí complementaridade e não superposição. Quanto maior o espaço para publicações, melhor para os demógrafos.

Por outro lado, a revista multilíngüe resolveria de modo mais eficaz a questão da dificuldade da divulgação de nossos textos em português. Como se verificou, a solução representada pelo Projeto Rebep em inglês, executado em processo paralelo, sem nenhuma articulação com a Revista em português, revelou-se financeiramente inexeqüível. Em uma revista multilingüe, o autor teria a liberdade de escolher em qual dos quatro idiomas submeteria seu texto, assumindo com isso o ônus e o bônus de sua própria opção.

Esta e outras decisões fundamentais para o futuro da Rebep deverão ser tomadas pelo novo Conselho Editorial. Diante do contexto político-institucional atual e dos procedimentos e características adquiridas pela Rebep, sua maioridade plena significa, também, sua volta à instituição onde nasceu, desta vez passando para as mãos do novo editor, nosso colega e amigo abepiano de primeira hora, Carlos Eugenio de C. Ferreira. Contando com os recursos e avanços da instituição de apoio - Fundação Seade-, o novo editor possui cabedal suficiente para enfrentar os desafios que a Revista tem pela frente, consolidando o nível atingido e acompanhando os desenvolvimentos científico e tecnológico em que está inserida. Carlos Eugenio, ademais com "capacidade de convocatória" para incrementar a "gaveta" da Revista, seguramente contribuirá decisivamente para o seu desenvolvimento em sua etapa "adultajovem".

ABEP. Índice. Revista Brasileira de Estudos de População, São Paulo: Abep, v.5, n.1 jan./jun., p. 1-63, 1988.

ABEP. Revista Brasileira de Estudos de População, São Paulo: Abep, v. 4, n.1, jan./jun., 1987. 
BOGUE, D. How Demography was born. Demography, v.30, n.4, p. 519-521, 1993.

CALDWELL, J.C. Demography and Social Sciences. Population Studies, v.50, November, p. 305-333, 1996.

COMITÊ EDITORIAL. Apresentação. Revista Brasileira de Estudos de População, São Paulo: Abep, v.1 n.1/2, p. 2, 1984.

HAUSER, P.M., DUNCAN, O.D. Panorama general y conclusiones. In: HAUSER, P.M., DUNCAN, O.D. (Eds.). El estudio de la población. Santiago: Celade, v.1, p. 1-38, 1975.

OLIVEIRA, M.C. Editorial. Revista Brasileira de Estudos de População, São Paulo: Abep, v.7, n.1/2, jan./dez., p. 124, 1990.

SALES, T. Editorial. Revista Brasileira de Estudos de População. São Paulo: Abep, v.11, n.1 jan./jun., p. 2, 1994.

TEACHMAN, J.D., PAASCH, K. et al. Thirty years of Demography. Demography, v.30, n.4, p. 523-532, 1993.

\begin{abstract}
Revista Brasileira de Estudos de População: from birth to age 21

This article consists of a discussion on the founding and maturing of the Revista Brasileira de População, which, in this special issue, is celebrating its "coming of age," its 21st anniversary. Resulting from the first activities on population in Brazil, Rebep was born at a historical moment of inflection in the evolution of demographic studies. The article represents an analysis of its evolution in terms of the characteristics, specificities and dynamics of this process, as well as in the light of the international changes that characterized those decades and in view of the development of the social sciences in Brazil, on which its specific character is based. The present discussion, then, can be seen as a tribute to the many colleagues who participated in its history. It can also be seen as a contribution to the reflections on the future of Abep itself, which is about to celebrate its 30th anniversary.
\end{abstract}

Key words: Rebep. Demography. Population studies. Themes on demographic analysis. Sources of data. Brazil. 